\title{
Opioids Suppress IPSCs in Neurons of the Rat Medial Septum/Diagonal Band of Broca: Involvement of $\mu$-Opioid Receptors and Septohippocampal GABAergic Neurons
}

\author{
Meenakshi Alreja, ${ }^{1,3}$ Marya Shanabrough, ${ }^{2}$ Weimin Liu, ${ }^{1}$ and Csaba Leranth ${ }^{2,3}$ \\ Departments of ${ }^{1}$ Psychiatry, ${ }^{2}$ Obstetrics and Gynecology, and ${ }^{3}$ Neurobiology, Yale University School of Medicine and the \\ Ribicoff Research Facilities, Connecticut Mental Health Center, New Haven, CT 06508
}

\begin{abstract}
The medial septum/diagonal band region (MSDB), which provides a major cholinergic and GABAergic input to the hippocampus, expresses a high density of opioid receptors. Behaviorally, intraseptal injections of opioids produce deficits in spatial memory, however, little is known about the electrophysiological effects of opioids on MSDB neurons. Therefore, we investigated the electrophysiological effects of opioids on neurons of the MSDB using rat brain slices. In voltage-clamp recordings with patch electrodes, bath-applied met-enkephalin, a nonselective opioid receptor agonist, decreased the number of tetrodotoxin and bicuculline-sensitive inhibitory synaptic currents in cholinergic- and GABA-type MSDB neurons. A similar effect occurred in brain slices containing only the MSDB, suggesting that opioids decrease GABA release primarily by inhibiting spontaneously firing GABAergic neurons located within the MSDB. Accordingly, in extracellular recordings, opioid-sensitive, spontaneously firing neurons could be found
\end{abstract}

within the MSDB. Additionally, in intracellular recordings a subpopulation of GABA-type neurons were directly inhibited by opioids. All effects of met-enkephalin were mimicked by a $\mu$ receptor agonist, but not by $\delta$ or $\kappa$ agonists. In antidromic activation studies, $\mu$-opioids inhibited a subpopulation of septohippocampal neurons with high conduction velocity fibers, suggestive of thickly myelinated GABAergic fibers. Consistent with the electrophysiological findings, in double-immunolabeling studies, $20 \%$ of parvalbumin-containing septohippocampal GABA neurons colocalized the $\mu$ receptor, which at the ultrastructural level, was found to be associated with the neuronal cell membrane. Thus, opioids, via $\mu$ receptors, inhibit a subpopulation of MSDB GABAergic neurons that not only make local connections with both cholinergic and noncholinergictype MSDB neurons, but also project to the hippocampus.

Key words: septohippocampal; GABA; opioids; parvalbumin; septum; diagonal band of Broca
The medial septum/diagonal band region (MSDB), which participates in learning and memory processes via its cholinergic and GABAergic projections to the hippocampus, also expresses one of the highest densities of opioid receptors in the brain. The opioid innervation to the MSDB, which is comprised primarily of $\beta$ endorphin-immunoreactive fibers and terminals (Watson et al., 1977; Bloom et al., 1978; Finley et al., 1981; Costa et al., 1983), originates from the hypothalamic arcuate nucleus (Millan et al., 1984). Intraseptal injections of opioids have been reported to both increase (Botticelli and Wurtman, 1982) and decrease hippocampal acetylcholine turnover (Moroni et al., 1978) in a naltrexonereversible manner. Behaviorally, intraseptal injections of opioids impair spatial memory, and intraseptal injections of naltrexone enhance memory function, indicating that opioid activity in the MSDB may normally participate in the regulation of memory processes (Bostock et al., 1988; Ragozzino et al., 1992). In addition to participating in learning and memory processes, the septal area, which is regarded as part of the reward circuit, may also

Received Sept. 24, 1999; revised Nov. 18, 1999; accepted Nov. 22, 1999.

This work was supported by National Institutes of Health Grants DA09797 to Meenakshi Alreja and NS26068 to Csaba Leranth. We thank N. Margiotta for technical help and Leslie Rosello for help in manuscript preparation.

Correspondence should be addressed to Meenakshi Alreja, Department of Psychiatry, CMHC 335, Yale University School of Medicine, 34 Park Street, New Haven, CT 06508. E-mail: Meenakshi.Alreja@yale.edu.

Copyright (C) 2000 Society for Neuroscience $0270-6474 / 00 / 201179-11 \$ 15.00 / 0$ contribute to the addictive properties of opioids. Rats have been known to self-administer opioids intraseptally (Stein and Olds, 1977; Bozarth, 1983), and a marked increase in glucose utilization (Kimes and London, 1988) and c-fos immunoreactivity occurs in the MSDB after opioid withdrawal (Couceyro and Douglass, 1995; Bot and Chahl, 1996).

The cellular targets of opioids in the MSDB that may underlie the above behavioral actions of opioids remain unknown. The few available studies on the electrophysiological actions of opioids in the septal area involve extracellular recordings from unidentified neurons. In in vivo studies on anatomically undefined neurons of the preoptic/septal region and the medial septal region, iontophoretically applied met-enkephalin, morphine, and endorphin have been reported to produce naloxone-reversible postsynaptic inhibitory effects (French and Siggins, 1980; Baldino and Beckman, 1982; Carette and Poulain, 1982). Intracellular and pharmacological studies on the effects of opioids on MSDB neurons are lacking. As such, the goal of the present study was to study the physiological and pharmacological action of opioids on electrophysiologically characterized rat MSDB neurons. Studies were performed using extracellular, intracellular, and whole-cell patch clamp recording techniques in an in vitro rat brain slice preparation; antidromic activation studies were used to identify septohippocampal MSDB neurons. Additional studies on the anatomical localization of opioid receptors on septohippocampal neurons were performed using single- and double-immunolabeling techniques at the light and electron-microscopic level. 


\section{MATERIALS AND METHODS}

Preparation of brain slices. Brain slices containing the MSDB were prepared from young adult male Sprague Dawley albino rats (3- to 4-weeksold, body weight, $80-130 \mathrm{gm}$ ) using methods detailed previously (Alreja and Liu, 1996). Briefly, rats were anesthetized with chloral hydrate (400 $\mathrm{mg} / \mathrm{kg}$, i.p.) and killed by decapitation. To enhance the yield of healthy cells, brain slices were prepared using artificial CSF (ACSF) in which the $\mathrm{NaCl}$ was initially replaced with an equiosmolar concentration of sucrose (Alreja and Aghajanian, 1995). The ACSF, pH 7.35-7.38, equilibrated with $95 \% \mathrm{O}_{2}$ and $5 \% \mathrm{CO}_{2}$, contained (in $\mathrm{mM}$ ): $\mathrm{NaCl}, 126 ; \mathrm{KCl}, 3$; $\mathrm{NaH}_{2} \mathrm{PO}_{4}, 1.25$; D-glucose, $10 ; \mathrm{NaHCO}_{3}, 25 ; \mathrm{CaCl}_{2}, 2$, and $\mathrm{MgSO}_{4}, 2$. After decapitation, the brain was removed and placed in a Petri dish containing sucrose ACSF and trimmed to yield a small block containing the MSDB. Coronal or sagittal slices of $\sim 500 \mu \mathrm{m}$ thickness containing the MSDB were cut with a vibrating-knife microtome (Frederick Haer) and transferred to the stage of a gas-liquid interface type of brain slice chamber over which humidified $95 \% \mathrm{O}_{2}$ and $5 \% \mathrm{CO}_{2}$ flowed. The stage temperature was gradually raised from room temperature to $33 \pm 0.5^{\circ} \mathrm{C}$ over $\sim 20 \mathrm{~min}$. One to $2 \mathrm{hr}$ later the slice was used for recording. The chamber was continuously perfused with normal ACSF at a rate of 1-2 $\mathrm{ml} / \mathrm{min}$. Although most recordings were performed in coronal slices, sagittal slice preparations containing the dorsal fornix were used for the antidromic activation studies.

In most recordings from coronal slices, the slice preparation also included the lateral septum, the bed nucleus of the stria terminalis, parts of the striatum, and the ventral pallidum. However, in some coronal slice preparations, the MSDB was isolated from all neighboring structures (including the lateral septum) by knife cuts, such that the slice contained only the MSDB (see Fig. 5B, stippled area). The purpose of these experiments was to study the effects of opioids on MSDB neurons independent of any inputs from neighboring structures (see Results).

Electrophysiological recordings were made primarily from the medial septum and from the vertical limb of the diagonal band of Broca.

Intracellular recordings. Intracellular recordings were performed using sharp microelectrodes (25-35 $\mathrm{M} \Omega$ resistance) filled with $2 \mathrm{M} \mathrm{KCl}$. All recordings were made using an Axoclamp-2A (Axon Instruments, Foster City, CA) amplifier either in the bridge mode or in the discontinuous single-electrode voltage-clamp mode. In current-clamp recordings, the output signal was filtered at $10 \mathrm{kHz}$.

The cells selected for study had spike amplitudes of 70-100 mV. The electrophysiological criteria for identification of cholinergic and noncholinergic-type (presumably GABAergic) neurons were based on those defined in the guinea pig and rat septum by earlier workers (Griffith and Matthews, 1986; Griffith, 1988; Markram and Segal, 1990; Gorelova and Reiner, 1996). Spike durations were measured at half-spike amplitude. In spontaneously firing cells these measurements were done at the resting potential and in quiescent cells, firing was evoked by injecting a small amount of depolarizing current. Input resistance was calculated by measuring the instantaneous voltage after injection of a hyperpolarizing current. The effects of bath-applied opioids on synaptic events were recorded only after chloride loading appeared complete ( $\sim 10-20 \mathrm{~min})$.

Discontinuous single-electrode voltage-clamp recordings were performed using previously described methods (Alreja, 1996). The cells were voltage-clamped at $-60 \mathrm{mV}$. The input impedance of each cell was continually monitored by stepping the membrane potential to -65 or $-70 \mathrm{mV}$ for $1 \mathrm{sec}$ at $20 \mathrm{sec}$ intervals. The current and voltage signals were amplified and displayed on storage oscilloscopes and also continuously recorded on a chart recorder (Gould 2200).

Whole-cell recordings, acquisition, and analysis of synaptic currents. Whole-cell patch-clamp recordings were performed using previously described methods (Alreja and Liu, 1996). In brief, low-resistance (2.5$3.5 \mathrm{M} \Omega$ ) patch pipettes were filled with a solution containing (in $\mathrm{mM}$ ): $\mathrm{K}$ gluconate, 120; HEPES, 10; BAPTA $\mathrm{K}_{4}, 5$; sucrose, 20; $\mathrm{CaCl}_{2}, 2.38$; $\mathrm{MgCl}_{2}, 1 ; \mathrm{K}_{2} \mathrm{ATP}, 1$, and GTP, 0.1, $\mathrm{pH}$ 7.32-7.35. A few experiments were done with $\mathrm{KCl}$ - and $\mathrm{CsCl}$-containing pipette solutions. Because most recordings were performed with $\mathrm{K}$ gluconate-containing solutions (wherein the polarity of the IPSCs was normal and not reversed in the depolarizing direction), no attempts were made to block spontaneously occurring spikes, especially because spike characteristics were useful in the characterization of cholinergic and noncholinergic-type neurons.

Synaptic currents were recorded using the continuous single-electrode voltage-clamp mode. The series resistance was continually monitored, and cells were used for recording only if the series resistance was $<6 \mathrm{M} \Omega$. Series resistance compensation was not done. If the series resistance increased during the course of the experiment and caused significant reductions in the IPSC amplitudes, efforts were made to improve access by applying one of several maneuvers (such as applying additional suction or slight positive pressure), failing which the experiment was discontinued.

Spontaneously occurring IPSCs were filtered at $3 \mathrm{kHz}$, amplified $100 \times$, and digitized at $15 \mathrm{kHz}$ (to minimize distortions in the fast rising phase of the synaptic currents) using the Digidata 1200 (Axon Instruments). With gluconate-containing electrodes, IPSCs were usually acquired at a holding potential of $-60 \mathrm{mV}$ (unless otherwise stated). The reversal potential of the IPSCs was estimated by observing the amplitude and polarity of the IPSCs in each cell at different holding potentials ranging from -60 to $-120 \mathrm{mV}$. With $\mathrm{Cl}^{-}$-containing electrodes IPSCs were recorded at $-90 \mathrm{mV}$. Ten $1 \mathrm{sec}$ sweeps of IPSCs were collected over 12-60 sec for each experimental condition. Spontaneously occurring EPSCs were blocked by bath application of the NMDA and non-NMDA antagonists AP-5 $(50 \mu \mathrm{M})$ and CNQX $(20 \mu \mathrm{M})$.

Off-line analysis of IPSCs was performed using the commercially available computer software package Axograph 2.0 (Axon Instruments), wherein the traces were visually inspected for synaptic events and manually marked using the mouse-measure command. This method ensured that the analysis was not corrupted by any slight change in the noise level or by membrane fluctuations. If the background noise increased during the recording, the data from that cell was discarded. The data generated from these measurements were used to plot cumulative probability amplitude and interevent interval graphs, with each distribution normalized to a maximal value of 1 . Cumulative probability plots obtained under different experimental conditions were compared using the nonparametric Kolmogorov-Smirnov test (K-S test), which estimates the probability that two cumulative distributions differ from each other by chance alone (Van Der Kloot, 1991; Lupica, 1995). The significance level for the K-S test was set at a conservative value of $p<0.01$. All numerical values are plotted as mean \pm SEM.

Antidromic activation of septohippocampal neurons and extracellular recordings. Extracellular recordings were made from spontaneously firing MSDB neurons with glass micropipettes filled with $2 \mathrm{M} \mathrm{NaCl}(5-10 \mathrm{M} \Omega$ ), and the fornix was stimulated using a bipolar Teflon-coated tungsten electrode. Septohippocampal projection neurons (SHNs) were identified by their antidromic response to electrical stimulation of the dorsal fornix (square pulses of $0.1-0.3 \mathrm{msec}$ duration, $40-1000 \mu \mathrm{A}$ ) using the following criteria: fixed latency of activation, high frequency following and collision of the antidromic spikes with orthodromic spikes (see Fig. 7). Similar criteria have previously been used to identify septohippocampal neurons in vivo (Lamour et al., 1984) and in vitro (Alreja and Liu, 1996; Liu and Alreja, 1997; Liu et al., 1998). The threshold of activation and the latency of antidromic activation were measured for each SHN, and the latency measurement was used to compute the conduction velocity for each SHN. The distance between the stimulating and the recording electrodes was measured using a calibrated graticule located in the eyepiece of the dissection scope.

Reagents. All constituents of the ACSF and the patch pipette solution were obtained from Mallinckrodt and Sigma (St. Louis, MO), respectively. The tetrapotassium salt of BAPTA was obtained from Molecular Probes (Eugene, OR). Bicuculline methiodide, tetrodotoxin (TTX), and Met-enkephalin were obtained from Sigma. D-Ala ${ }^{2}, N$-Me-Phe ${ }^{4}, \mathrm{Gly}_{-} \mathrm{ol}^{5}$ Enkephalin (DAMGO), [D-Pen $\left.{ }^{2,5}\right]-$ Enkephalin (DPDPE), and ( \pm )trans-U50488 methanesulfonate (U50,488H), CTOP, 6-cyano-2,3-dihydroxy-7-nitroquinoxaline (CNQX), and DL-2-aminophosphonovaleric acid (AP-5) were obtained from Research Biochemicals (Natick, MA).

All drugs were diluted in ACSF from previously prepared stock solutions that were prepared in water (unless mentioned otherwise) and stored at $-20^{\circ} \mathrm{C}$. All drugs were bath-applied by turning a three-way valve that switched from ACSF to the test solution. The turnover time of the recording chamber was $<30 \mathrm{sec}$.

Double label fluorescent immunocytochemistry. Rats were perfused with a fixative containing $4 \%$ paraformaldehyde, $15 \%$ picric acid, and $0.1 \%$ glutaraldehyde in phosphate buffer (PB). A tissue block containing the septum was dissected from the brain and was post-fixed in glutaraldehyde-free fixative for $1 \mathrm{hr}$. Fifty micrometer sections were cut on a Vibratome (Lancer) and washed thoroughly (four times for $10 \mathrm{~min}$ each) in PB between each of the following incubation steps. First, sections were transferred into a vial containing $1 \mathrm{ml}$ of $10 \%$ sucrose in $\mathrm{PB}$. The vial was slowly immersed and frozen in liquid nitrogen and then 
A

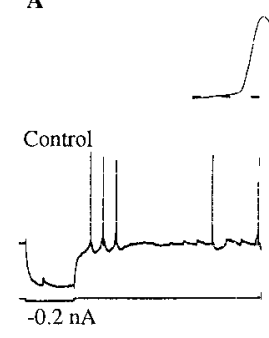

B

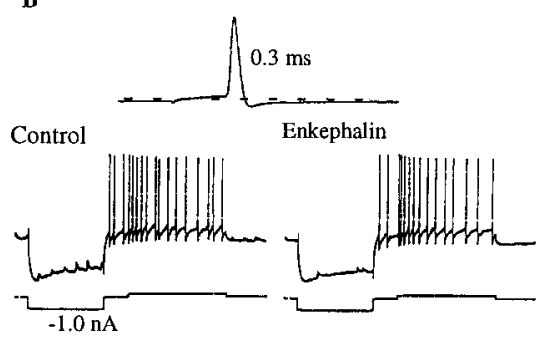

C

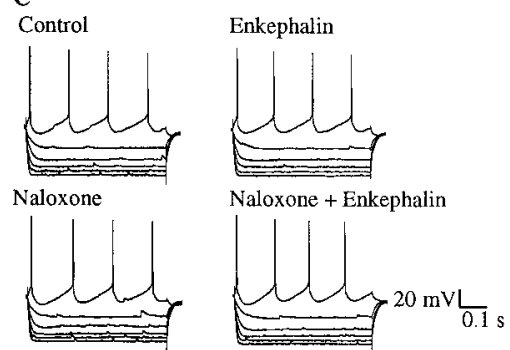

Figure 1. Bath applications of met-enkephalin, a nonselective opioid agonist, decreases synaptic activity in both cholinergic and noncholinergic-type MSDB neurons. $A, B$, Intracellular recordings with $\mathrm{KCl}$-containing electrodes show cholinergic and noncholinergic-type MSDB neurons. $A$, A spontaneously firing broad-spiked cholinergic-type MSDB neuron (spike duration, $0.8 \mathrm{msec}$ ). Note the prominent slow afterhyperpolarization, which is characteristic of septal cholinergic neurons. Note that bath-applied met-enkephalin $(100 \mu \mathrm{M})$ decreased depolarizing synaptic potentials in this neuron. $B$, Met-enkephalin also decreased the number of depolarizing synaptic potentials in a quiescent, sharp-spiked, noncholinergic-type (presumably GABAergic) MSDB neuron (spike duration, $0.3 \mathrm{msec}$ ). Note the prominent fast afterhyperpolarization and the depolarizing sag (in response to the hyperpolarizing pulse) that are characteristic of MSDB GABAergic neurons. $C$, The nonselective opioid antagonist naloxone blocked the inhibitory effect of enkephalin on spontaneously occurring synaptic potentials.

allowed to thaw at room temperature. After this, the tissue was incubated for $15 \mathrm{~min}$ in $1 \%$ sodium borohydride in PB to remove excess aldehydes. Then, the tissue was incubated overnight at room temperature in a mixture of antibodies containing polyclonal rabbit anti-opioid $\mu$ receptor (1:500; Ab-1; Calbiochem, Cambridge, MA) plus monoclonal mouse anti-parvalbumin (1:5000; Sigma), both diluted in PB plus $0.1 \%$ sodium azide. This was followed by an incubation in the dark for $2 \mathrm{hr}$ at room temperature in a mixture of secondary antibodies consisting of goat anti-rabbit IgG-fluorescein (1:50 in PB; Vector Laboratories, Burlingame, CA) plus horse anti-mouse IgG-Texas Red (1:50 in PB; Vector Laboratories). Sections were then wet mounted onto slides, examined under an Olympus fluorescent scope using the appropriate filter for each fluorochrome, and the images were captured.

Mirror colocalization technique. The mirror colocalization technique of Kosaka et al. (1985) was used. Consecutive vibratome sections of the septum (20 pairs of sections per animal; a total of three animals) were placed in alternate wells of a 24-well tissue culture plate. Every other section was immunostained for parvalbumin (PA) while each corresponding serial section was immunolabeled for $\mu$-opioid receptor. In this experiment, a polyclonal rabbit anti-PA (1:3000; a gift of Dr. Kenneth G. Baimbridge, University of British Columbia, Vancouver, British Columbia, Canada) and a rabbit anti- $\mu$-opioid receptor antibody (1:2500; Calbiochem) were used. Each antiserum was diluted in $1 \%$ normal goat serum in PB containing $0.1 \%$ sodium azide. Sections were incubated in the primary antisera overnight at room temperature. This was followed by incubation in the secondary antiserum, biotinylated anti-rabbit $\mathrm{IgG}$ (1:250 in PB; Vector Laboratories), and then, in avidin-biotin-peroxidase (ABC Elite, 1:50 in PB; Vector Laboratories), each for $2 \mathrm{hr}$ at room temperature. The tissue-bound peroxidase was visualized with a diaminobenzidine (DAB) reaction ( $15 \mathrm{mg} \mathrm{DAB}, 165 \mu \mathrm{l}$ of $0.3 \% \mathrm{H}_{2} \mathrm{O}_{2}$ in $30 \mathrm{ml}$ $\mathrm{PB}$ ). The sections were washed (four times for $10 \mathrm{~min}$ each) between each incubation step. Consecutive sections were mounted on slides (two sections per slide; one immunostained for PA and the other for $\mu$-opioid receptor) in such a way that the posterior side of the first section and the anterior side of the second section were face up. Slides were dehydrated and coverslipped in Permount. Light-microscopic examination and photographs were taken from consecutive sections of the same identified perikarya to determine colocalization of the two substances.

Immunostaining for electron microscopy. Sections for electron microscopy were first incubated in a $1 \%$ sodium borohydride in PB solution. After thorough washing, the sections were freeze-thaw-treated (see above). Immunostaining for $\mu$-opioid receptor was performed using the same protocol as for the mirror colocalization technique. After the DAB reaction, sections were postosmicated (1\% OsO4 in $\mathrm{PB}$ for $15 \mathrm{~min})$, dehydrated through increasing concentrations of ethanol (the $70 \%$ ethanol contained $1 \%$ uranyl acetate, $30 \mathrm{~min}$ ), and then embedded in Araldite. Ultrathin sections were cut on a Reichert-Jung ultramicrotome, placed on Formvar-coated single-slot grids, and examined under a Philips CM-10 electron microscope.

\section{RESULTS
Met-enkephalin suppresses inhibitory synaptic activity in both cholinergic and noncholinergic-type MSDB neurons}

In intracellular recordings performed with sharp microelectrodes containing $\mathrm{KCl}$, both cholinergic-type and noncholinergic type neurons were observed in the MSDB (Fig. 1). Bath-application of the nonselective opioid agonist, met-enkephalin $(10-100 \mu \mathrm{M}$; in absence of peptidase inhibitors) decreased the number of spontaneously occurring depolarizing synaptic potentials in both types of MSDB neurons. This effect was blocked by the nonselective opioid antagonist naloxone $(n=3$; Fig. 1$)$. In whole-cell recordings with $\mathrm{K}$ gluconate-containing electrodes, the effect of bath-applied met-enkephalin was seen as a decrease in the number of hyperpolarizing synaptic potentials. These observations suggested that the depolarizing synaptic potentials recorded with $\mathrm{Cl}^{-}$-containing electrodes may in fact be reverse IPSPs (see below).

To further analyze the effect of met-enkephalin on synaptic activity in MSDB neurons, recordings were performed in the voltage-clamp mode using low-resistance whole-cell electrodes containing $\mathrm{K}$ gluconate or $\mathrm{CsCl}$. Spontaneously occurring IPSCs were observed in $58.2 \%$ of the neurons tested (39 of 67); metenkephalin inhibited the spontaneously occurring IPSCs in $56.4 \%$ (22 of 39) of the cells tested (Fig. 2). The amplitude and polarity of the opioid-sensitive IPSCs varied with changes in $E_{\mathrm{Cl}^{-}}$. Thus, with gluconate-containing electrodes (calculated $E_{\mathrm{Cl}^{-}}$ $=-80 \mathrm{mV}$ ), the amplitude of the spontaneous synaptic currents decreased at more negative holding potentials and reversed polarity between -80 and $-100 \mathrm{mV}$ in all cells tested. The actual reversal potential was $-88 \pm 6 \mathrm{mV}$ (Fig. 2). In recordings with chloride-containing electrodes (calculated $E_{\mathrm{Cl}^{-}}=1.5 \mathrm{mV}$ ), the opioid-sensitive synaptic activity was reversed in polarity (see Figs. 1, 4, 5), and the amplitude of the synaptic events increased at more negative holding potentials.

As mentioned above, neurons that exhibited enkephalinsensitive synaptic activity did not have similar electrophysiological characteristics but belonged to two classes of electrophysiologically distinct subgroups (Fig. 1). Of a total of 67 neurons tested using whole-cell electrodes, 24 neurons were electrophysiologically identified as cholinergic-type, and the remaining 43 as noncholinergic (presumably GABAergic). This characterization 

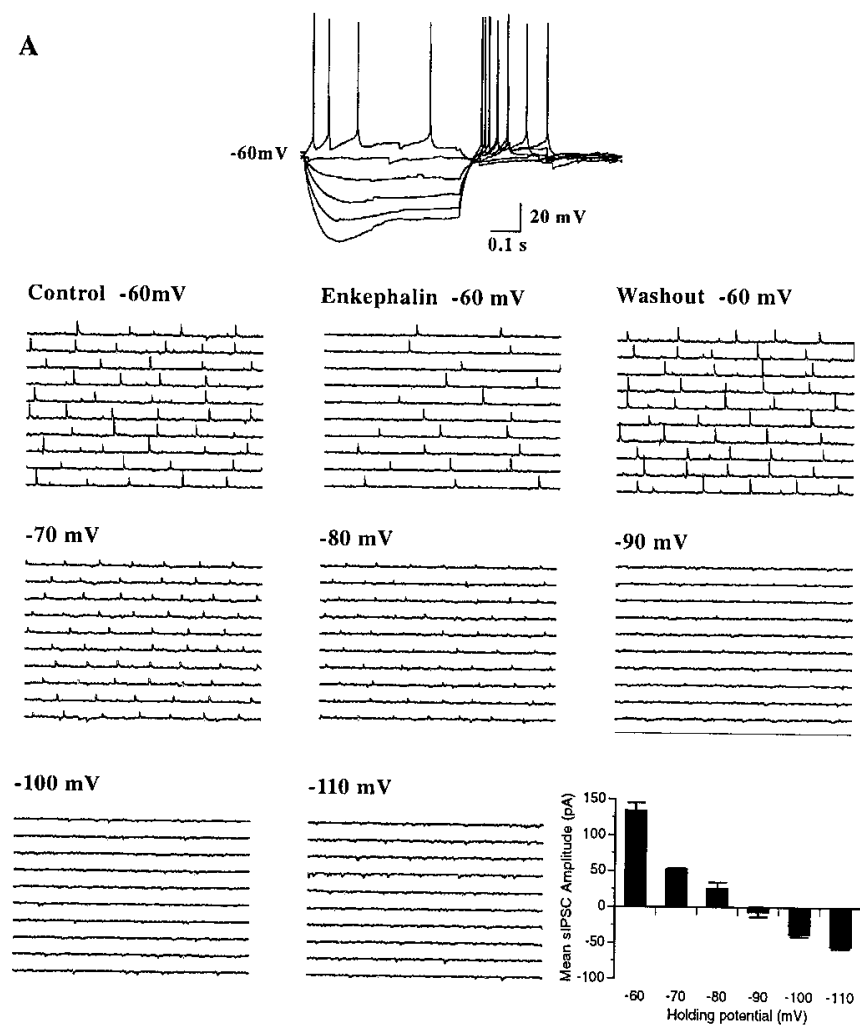

$\mathbf{B}$
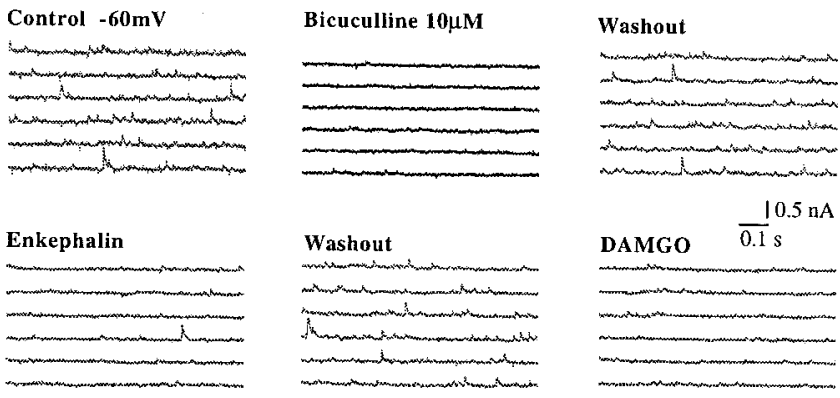

Figure 2. Met-enkephalin-sensitive synaptic activity reverses polarity near the chloride equilibrium potential and is blocked by the $\mathrm{GABA}_{\mathrm{A}}$ receptor antagonist bicuculline. $A$, Whole-cell current-clamp recording from a GABA-type MSDB neuron with a K-gluconate-containing patch electrode. Note the fast afterhyperpolarization and the depolarizing sag. Consecutive $0.5 \mathrm{sec}$ traces show spontaneously occurring IPSCs recorded under different experimental conditions. The first sets of traces show IPSCs recorded at $-60 \mathrm{mV}$ under control conditions, with metenkephalin and after washout of met-enkephalin. Subsequent sets of traces show IPSCs recorded under control conditions at different holding potentials (ranging from -60 to $-120 \mathrm{mV}$ ). Note the changes in amplitude and polarity of the synaptic currents at different holding potentials. The bar chart summarizes the data shown above. The mean IPSC amplitude under control conditions is plotted against different holding potentials. Note that the mean amplitude of the met-enkephalin-sensitive IPSCs decreased at more negative holding potentials and reversed polarity between -80 and $-90 \mathrm{mV}$, which is close to the calculated $E_{\mathrm{Cl}^{-}}$of -80 $\mathrm{mV}$. This experiment was done in presence of $20 \mu \mathrm{M}$ CNQX and $50 \mu \mathrm{M}$ AP-5 to block excitatory synaptic currents. $B$, In this cell, bicuculline blocked the spontaneously occurring IPSCs in a reversible manner. Subsequent sets of traces show the inhibitory effect of met-enkephalin. Note that the $\mu$-selective opioid receptor agonist DAMGO mimicked the effect of met-enkephalin. All drugs were applied consecutively to the same cell. was based on criteria previously defined by other investigators (Griffith and Matthews, 1986; Griffith, 1988; Markram and Segal, 1990; Gorelova and Reiner, 1996). Cells classified as cholinergictype (Fig. $1 A)$ had broad spikes $(0.7-1.3 \mathrm{msec})$ and prominent slow afterhyperpolarizations (AHPs) showed classical rectification but lacked a prominent depolarizing sag in the electronic response to a hyperpolarizing pulse (Fig. 1C). Spontaneously occurring inhibitory synaptic activity was present in 11 of 24 cholinergic-type neurons tested; enkephalin suppressed this activity in 4 of 11 neurons tested; an opioid-induced outward current was observed in 2 of 24 neurons tested.

The remaining 43 cells, classified as noncholinergic-type (Figs. $1 B, 2,8 A)$ had shorter duration spikes $(0.25-0.5 \mathrm{msec})$, prominent fast AHPs, and most displayed depolarizing sags on hyperpolarization. Enkephalin suppressed spontaneously occurring synaptic activity in 20 of 43 neurons tested, and an opioid-induced outward current was observed in $25 \%$ of the neurons tested.

\section{Met-enkephalin suppressed IPSCs are GABAergic in nature and result from a firing of GABAergic neurons within the MSDB}

Because the above-mentioned data suggested that the opioidsensitive synaptic currents are inhibitory in nature, we hypothesized that the spontaneously occurring IPSCs that are observed in cholinergic and noncholinergic-type MSDB neurons may be originating from GABAergic neurons within the septal nuclei. Therefore, we tested the effect of bicuculline, a $\mathrm{GABA}_{\mathrm{A}}$ antagonist, and tetrodotoxin, a fast sodium channel blocker, on the opioid-sensitive $\mathrm{Cl}^{-}$-mediated synaptic activity. Both bicuculline (Fig. $2 B ; n=3$ ) and tetrodotoxin, a fast sodium channel blocker (Fig. 4; $n=4$ ), blocked the spontaneously occurring inhibitory synaptic activity, suggesting that a major effect of opioids in the MSDB is to inhibit IPSCs that are both trans-synaptic and GABAergic in nature. A comparison of the frequency and amplitude distribution of the sIPSCs was performed before and after bath application of met-enkephalin using patch electrodes containing $\mathrm{CsCl}(n=7)$. Met-enkephalin significantly altered both the frequency and the amplitude distribution of the sIPSCs, as assessed by the $\mathrm{K}-\mathrm{S}$ test (Figs. 3, 4). The change in the frequency and amplitude distributions of the sIPSCs presumably occurs because of an opioid-induced loss of action potentialdependent IPSCs after hyperpolarization of GABAergic neurons (Cohen et al., 1992; Lupica, 1995).

To determine if opioids have an additional effect on the TTXinsensitive spontaneous release of GABA from nerve terminals, we tested the effects of opioids and TTX on spontaneously occurring inhibitory synaptic currents recorded with patch electrodes containing $\mathrm{CsCl}$. $\mathrm{CsCl}$, by improving the integrity of the voltage clamp, enhances the detectability of miniature IPSCs (mIPSCs). As expected, opioid-sensitive IPSCs were blocked by TTX, however, despite the markedly improved signal-to-noise ratio with $\mathrm{CsCl}$ electrodes (noise level, 5-10 pA), TTXinsensitive mIPSCs were essentially undetectable in MSDB neurons in the four cells tested (Fig. 4), rendering it unfeasible to test the effect of opioids on mIPSCs in MSDB neurons. Thus, although the present study cannot rule out an effect of opioids on miniature IPSCs in MSDB neurons; it provides strong evidence that the primary effect of opioids in MSDB neurons is to inhibit impulse-dependent GABA release that is caused by firing of GABAergic neurons. We have adopted the term "spontaneous" to describe these TTX-sensitive events; thus, the term spontaneous IPSCs (sIPSCs) simply means the synaptic currents have not 

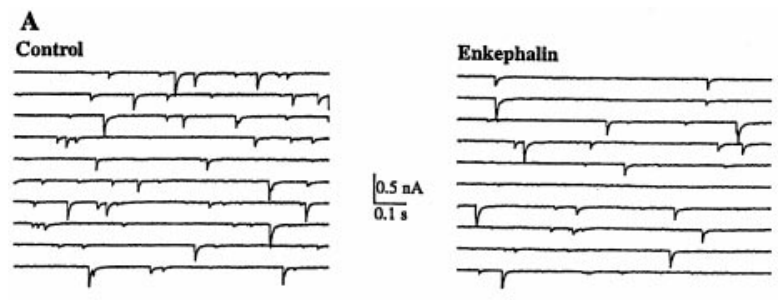

B

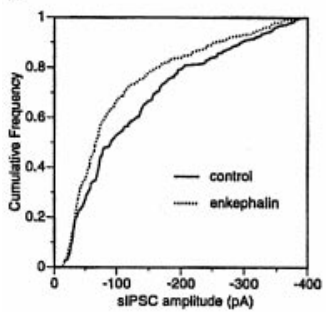

C
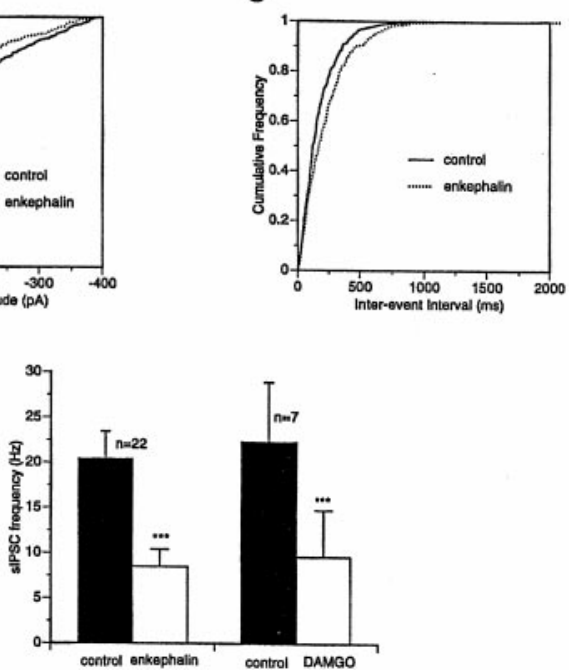

Figure 3. Opioids alter both the frequency and amplitude distribution of sIPSCs. $A$, Whole-cell voltage-clamp recording from an MSDB neuron with a CsCl-containing patch electrode. EPSCs were blocked using glutamate receptor antagonists (see Materials and Methods). Consecutive $0.5 \mathrm{sec}$ traces show spontaneously occurring IPSCs recorded at $-90 \mathrm{mV}$ before and after bath application of met-enkephalin. Note the reversed polarity of the IPSCs. $B, C$, Cumulative amplitude and frequency distributions of sIPSCs constructed from data shown in $A$. Note that both the amplitude and frequency distribution were statistically different under the two experimental conditions $(p<0.0001$ for amplitude distribution and $p<0.005$ for frequency distribution, 274 events analyzed for control and 222 events for met-enkephalin). This presumably reflects loss of action potential-dependent IPSCs after hyperpolarization of GABAergic neurons. $D$, Bar chart summarizes the effect of met-enkephalin and the $\mu$ agonist DAMGO on the frequency of sI PSCs recorded with $\mathrm{K}$ gluconate or CsCl-containing patch electrodes. Both met-enkephalin and DAMGO produced a significant decrease in the frequency of sIPSCs $(p<0.001$, Student's $t$ test).

been evoked via exogenous electrical stimulation and that sIPSCs are evoked by the action potential discharge of neurons and serve as an index of firing rate and hence excitability state of a neuron.

Theoretically, the opioid-sensitive inhibitory synaptic activity, that is TTX-sensitive, could originate from a firing of GABAergic neurons present within the MSDB or from GABA neurons present in other brain structures located within the slice preparation (Fig. $5 A$ ). Of the brain regions present in our slice preparation (Fig. $5 A$, stippled area), the lateral septum was of special interest because not only does it contain a large population of GABA neurons but also expresses opioid receptors; until recently the lateral septum was believed to provide a massive GABAergic input to the MSDB (Leranth et al., 1992). To determine whether the TTX-sensitive IPSCs that are inhibited by opioids originate from GABA neurons within the MSDB, we tested the effects of met-enkephalin in brain slices where the MSDB had been surgically isolated from all neighboring structures such as the lateral septum (Fig. 5B, stippled area). The opioids induced a similar decrease in synaptic activity in both types of slice preparations.
A
Control

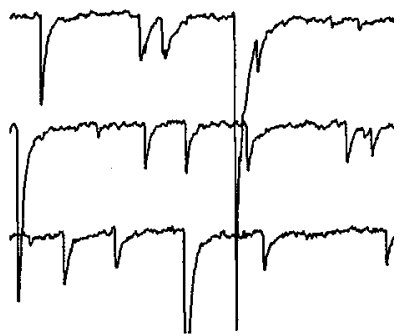

\section{DAMGO}

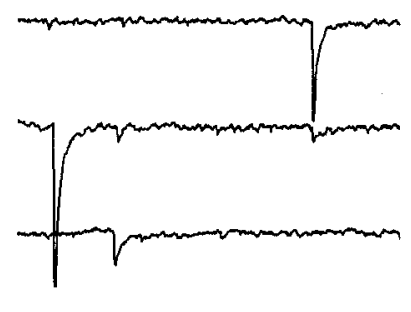

$0.1 \mathrm{nAL}$

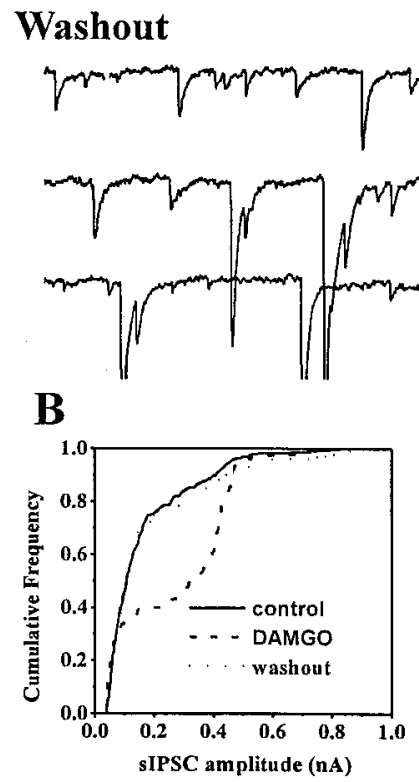

TTX

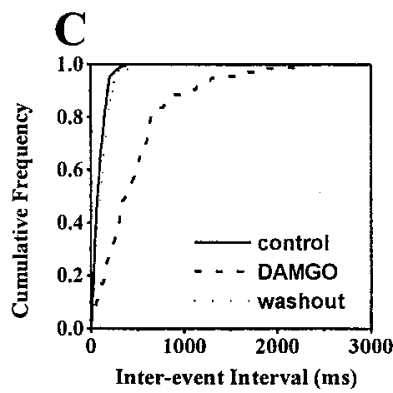

Figure 4. TTX blocks spontaneously occurring IPSCs in MSDB neurons. $A$, Whole-cell voltage-clamp recording from an MSDB neuron with a CsCl-containing patch electrode. EPSCs were blocked using glutamate receptor antagonists (see Materials and Methods). Consecutive $0.5 \mathrm{sec}$ traces show spontaneously occurring IPSCs recorded at $-90 \mathrm{mV}$ before and after bath application of DAMGO and in presence of TTX. Note that DAMGO blocked spontaneously occurring IPSCs and that a subsequent application of TTX blocked the IPSCs. $B, C$, Cumulative amplitude and frequency distributions of sIPSCs constructed from data shown in $A$. Note that both the amplitude and frequency distribution were statistically different in the presence of DAMGO $(p<0.0001$ for amplitude distribution and $p<0.005$ for frequency distribution as compared to control). This presumably reflects loss of action potential-dependent IPSCs after hyperpolarization of GABAergic neurons. The distributions recorded under control and washout conditions were not statistically different from each other.

Similar to the control slice preparation, in the isolated MSDB slice preparation, spontaneously occurring IPSCs were present in $54.5 \%$ of the neurons tested (6 of 11); met-enkephalin inhibited the spontaneously occurring IPSCs in four of six cells that showed spontaneously occurring IPSCs. Thus, the opioidsensitive synaptic activity that is observed in cholinergic and GABA-type MSDB neurons originates from GABA neurons and terminals present within the MSDB. Because most of the opioidsensitive synaptic activity in MSDB neurons is blocked by TTX, our results suggest that TTX-sensitive IPSCs that are suppressed 


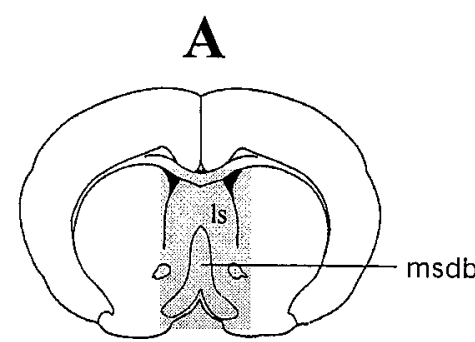

\section{Control}

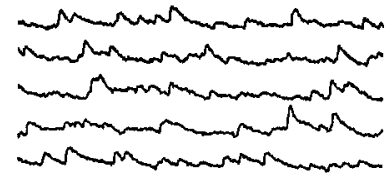

\section{Enkephalin}

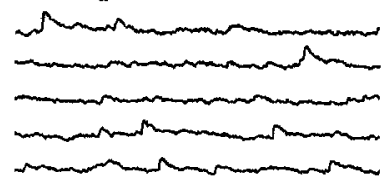

\section{Washout}

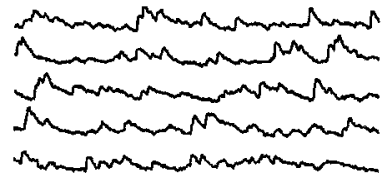

\section{DAMGO}
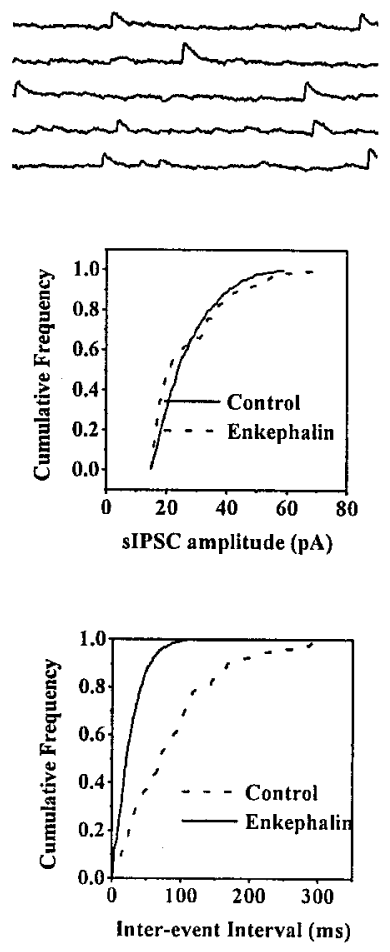

Figure 5. Opioid-sensitive IPSCs originate from within the MSDB. $A$, Consecutive $1 \mathrm{sec}$ traces show spontaneously occurring IPSCs recorded at a holding potential of $-60 \mathrm{mV}$ under different experimental conditions. This whole-cell recording was made in a slice preparation that contained the MSDB as well as other neighboring brain structures (stippled area),

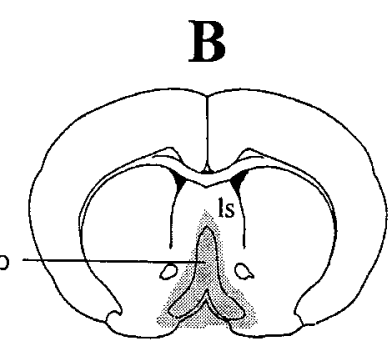

$\mathbf{A}$

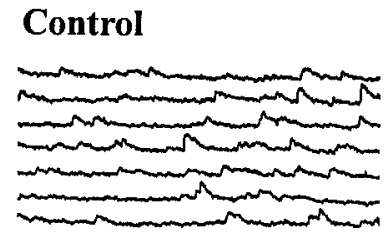

\section{Enkephalin}

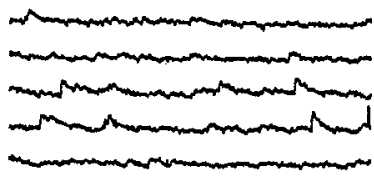

\section{Washout}

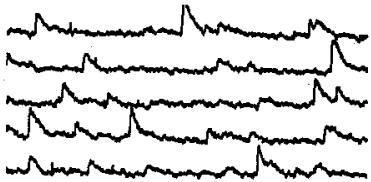

\section{DAMGO}
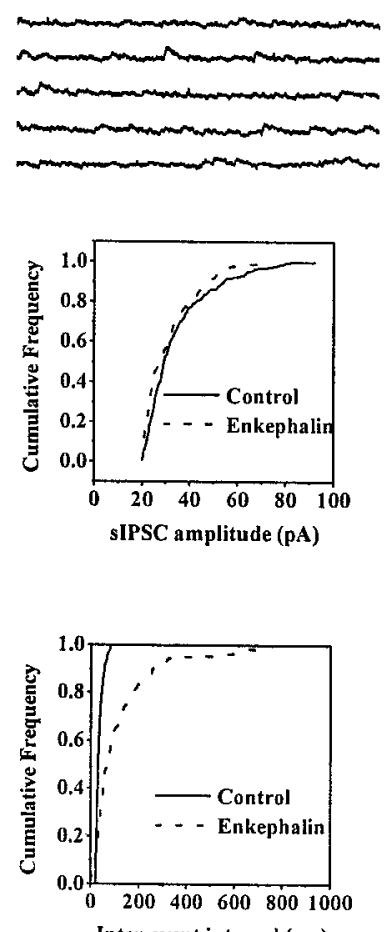

Inter-event interval (ms)

B
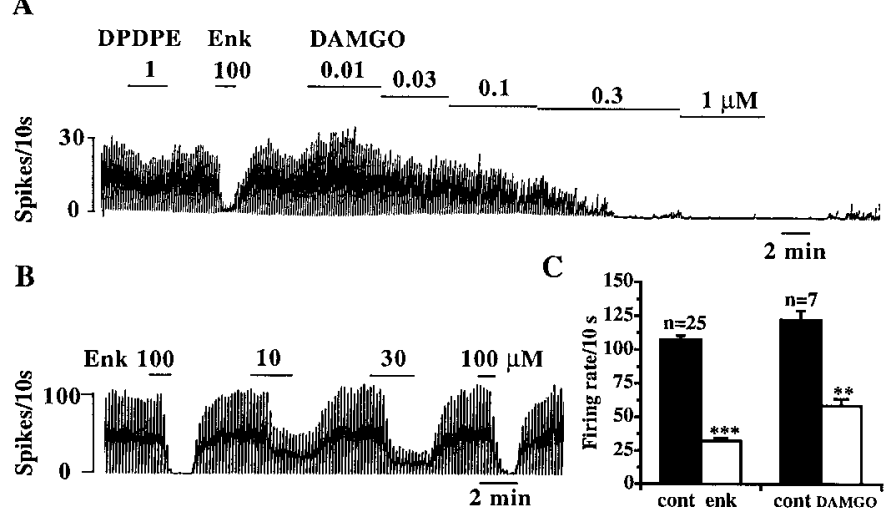

Figure 6. Opioids inhibit a subpopulation of spontaneously firing MSDB neurons. $A, B$, Extracellular recording from a spontaneously firing MSDB neuron showing the inhibitory effect of met-enkephalin. Note that the $\mu$ agonist DAMGO mimicked the inhibitory effect of met-enkephalin in a concentration-dependent manner and that DPDPE had very little effect. $C$, Summarizes the effect of met-enkephalin $(100 \mu \mathrm{M})$ and DAMGO (100 nM) on spontaneously firing MSDB neurons. The smaller effect of DAMGO as compared to met-enkephalin was caused by the submaximal concentration used $(A)$. An inhibitory effect of opioids was observed in $57 \%$ of spontaneously firing MSDB neurons tested.

by opioids originate from GABA neurons present within the MSDB.

The $\mu$-opioid receptor mediates the suppressive effect of opioids on IPSCs in MSDB neurons

Receptor mRNA (Mansour et al., 1994; Delfs et al., 1994; Zastawny et al., 1994) and autoradiographic studies (Goodman and Pasternak, 1985; Mansour et al., 1988) have revealed high levels of both $\mu$-and $\delta$-opioid receptor message in neurons of the MSDB. To determine the receptor subtype or subtypes mediating the effects of opioids on IPSCs, we tested the effect of DAMGO, a $\mu$-selective agonist, and DPDPE, a $\delta$-selective agonist, on metenkephalin-sensitive IPSCs (Figs. 2, 3D, 4, 5). DAMGO mimicked the effect of met-enkephalin and suppressed sIPSCs in all seven cells tested; DPDPE had little or no effect in any of the three cells tested. Note that DAMGO also mimicked the effect of enkephalin in slices that contained only the MSDB (Fig. 5B). To further confirm the involvement of the $\mu$-opioid receptor, we tested the effect of the $\mu$-selective antagonist CTOP. CTOP blocked the effect of met-enkephalin and DAMGO in the three cells tested (data not shown).

\section{Opioid-induced inhibition of septohippocampal GABA-type neurons}

Based on the above observations, we hypothesized the existence in the MSDB of a subpopulation of spontaneously firing GABAergic neurons that would be directly inhibited by opioids. As a first step, we looked for spontaneously firing neurons in the

such as the lateral septum $(l s)$. Note that met-enkephalin decreased the number of sIPSCs. Also note that this effect was mimicked by the selective $\mu$-opioid receptor agonist DAMGO, suggesting involvement of $\mu$-opioid receptors. $B$, This whole-cell recording was made from a brain slice that contained only the MSDB (stippled area). Note that the spontaneously occurring IPSCs were inhibited both by met-enkephalin and DAMGO. Because the slice preparation contained only the MSDB, it can be concluded that met-enkephalin and DAMGO suppress sIPSCs that originate from within the MSDB. The amplitude and frequency distributions were statistically different under control and test conditions. 


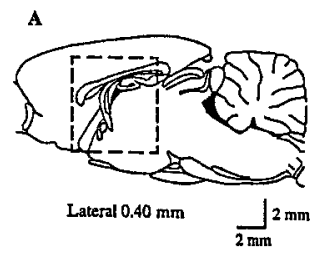

B
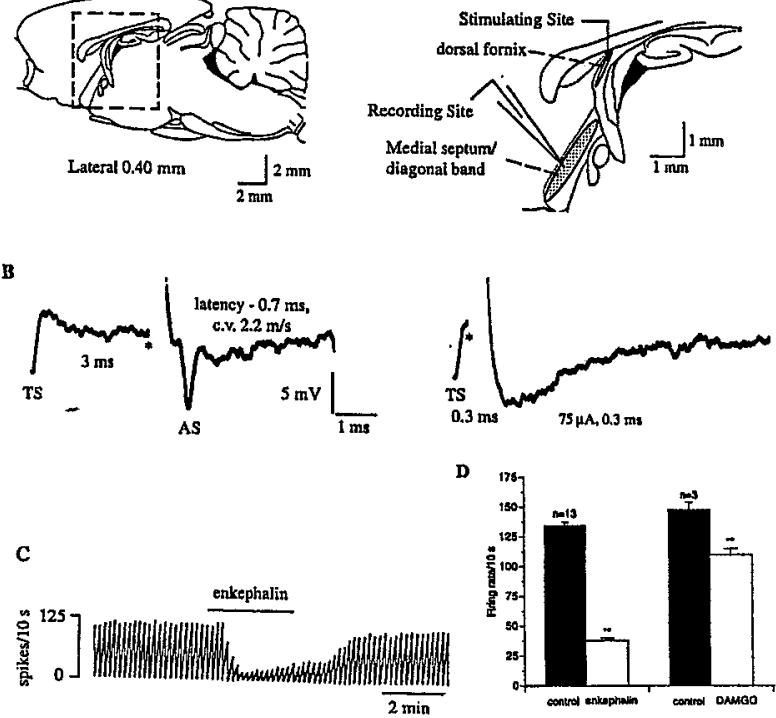

Figure 7. Opioids inhibit a subpopulation of spontaneously firing, antidromically activated septohippocampal neurons. $A$, Sagittal section through the rat brain, showing the septal area. The boxed area is enlarged (right) and shows the MSDB, which was the recording site. For antidromic activation of septohippocampal neurons, the stimulating electrode was placed in the dorsal fornix because it conveys both cholinergic and GABAergic MSDB fibers to the hippocampus. B, Extracellular recording from a spontaneously firing antidromically activated septohippocampal neuron. A spontaneous spike was used to trigger the oscilloscope $(T S)$, the dorsal fornix was stimulated (*) $3 \mathrm{msec}$ later, and an antidromically activated spike $(A S)$ was obtained after a latency of $0.7 \mathrm{msec}$ (left trace). This cell was classified as GABA-type based on the calculated conduction velocity of $2.2 \mathrm{~m} / \mathrm{sec}$. The right trace shows a positive collision test, wherein the cell could not be activated antidromically when the dorsal fornix was stimulated $0.3 \mathrm{msec}$ after the triggering spike (approximately half the antidromic latency). This and other cells were also confirmed to be antidromically activating using additional criteria (see Materials and Methods). Stimulation current, $75 \mu \mathrm{A}, 0.3 \mathrm{msec} . C$, Chart record showing the effect of met-enkephalin on the firing rate of a spontaneously firing septohippocampal neuron (same cell as shown in $B$, above). $D$, Summarizes the effect of a near-maximal concentration of met-enkephalin (100 $\mu \mathrm{M})$ and a submaximal concentration of DAMGO (100 nM) on antidromically activated SHNs. The smaller effect of DAMGO as compared to met-enkephalin was attributable to the submaximal concentration used (Fig. 6). An inhibitory effect of opioids was observed in $76 \%$ of spontaneously firing SHNs tested.

MSDB using the extracellular recording technique and tested the effect of opioid peptides on these spontaneously firing neurons. Consistent with our hypothesis, we found a subpopulation of spontaneously firing neurons that were inhibited by metenkephalin (57\% of the spontaneously firing cells tested; 25 of 44). The $\mu$-selective agonist DAMGO mimicked the effect of met-enkephalin in all seven cells tested; DPDPE had little effect in the two cells tested (Fig. 6A).

Because a subpopulation of MSDB GABAergic neurons project to the hippocampus, we next asked the question-do the spontaneously firing neurons that are inhibited by met-enkephalin project to the hippocampus? To answer this question, we tested the effect of met-enkephalin on 25 antidromically activated, spontaneously firing septohippocampal neurons recorded in sagittal brain slice preparation (Fig. $7 A$ ). Interestingly, $76 \%$ of the neurons tested (19 of 25 ) responded to met-enkephalin with a decrease in firing rate, and DAMGO mimicked the effect of enkephalin in all three cells tested (Fig. $7 B-D$ ). More importantly, all the neurons sensitive to met-enkephalin had fast conducting fibers with a mean conduction velocity of $1.83 \pm 0.14 \mathrm{~m} / \mathrm{sec}$ (range, 1.1-3.2 m/sec). Conduction velocities in this range are highly suggestive of GABAergic neurons (see Discussion). Figure $7 D$ is a summary of the abovementioned extracellular data on septohippocampal neurons.

In addition to having fast-conducting fibers, noncholinergic (presumably GABAergic) neurons have been reported to exhibit electrophysiological properties distinct from cholinergic-type neurons. We therefore made use of both the whole-cell and the sharp microelectrode intracellular recording technique to look for GABA-type neurons in the MSDB and tested the effect of opioids on their membrane properties. The GABA-type neurons tested had short-duration spikes $(0.4 \pm 0.02 \mathrm{msec})$, a prominent fast but not a slow AHP, and a low input resistance $(<125 \mathrm{M} \Omega)$. Some of the cells also exhibited a prominent depolarizing sag in response to hyperpolarizing pulses. Using whole-cell recordings with $\mathrm{K}$ gluconate-containing patch electrodes, we tested the effect of Met-enkephalin on 37 GABA-type neurons. Met-enkephalin had no effect in $37.8 \%$ (14 of 37) of the GABA-type neurons tested, and it reduced ongoing inhibitory synaptic activity by $59 \pm 5.8 \%$ in $45.9 \%$ of the cells tested (17 of 37 ). In $24.3 \%$ of the cells tested (9 of 37), met-enkephalin produced either a small hyperpolarization (under current-clamp conditions) or a small outward current (under voltage-clamp at $-60 \mathrm{mV}$ ). In intracellular electrodes with $\mathrm{KCl}$-containing sharp microelectrodes, met-enkephalin produced a similar membrane response in 8 of 27 cells tested $(29.6 \%)$. Thus, the percentage of GABA-type cells that responded to met-enkephalin did not vary with the type of recording used. The opioid-responsive GABA-type cells had a mean spike duration of $0.35 \pm 0.01 \mathrm{msec}$ and an input resistance of $91 \pm 15 \mathrm{M} \Omega(n=17)$; 12 of 17 cells were spontaneously firing; 14 of 17 cells displayed a prominent depolarizing sag in response to a hyperpolarizing pulse. The data from both these recordings is therefore summarized together.

Under voltage-clamp conditions at $-60 \mathrm{mV}$ met-enkephalin produced a small change in the holding current (range, 20-120 pA; mean, $45 \pm 11.4 \mathrm{pA} ; n=9$ ). This current was associated with an increase in input conductance (Fig. $8 B$ ), suggesting a net opening of channels. Current-voltage curves performed using slow steady-state ramps ( -60 to $-120 \mathrm{mV}$ in $10 \mathrm{sec}$ ) before and during opioid treatment revealed an increase in inward rectification and an outward current that reversed polarity close to the potassium equilibrium potential (data not shown). Under currentclamp conditions, the effect of met-enkephalin was observed as a 1-12 $\mathrm{mV}$ hyperpolarization (mean, $4.7 \pm 1.4 \mathrm{mV} ; n=9$; Fig. $8 A$ ). In the three cells tested, the opioid-induced outward current persisted in the presence of TTX, suggesting the presence of a direct postsynaptic effect. DAMGO mimicked the effect of enkephalin and produced an outward current in the three cells tested; the effect of met-enkephalin was also blocked by the $\mu$ antagonist CTOP. DPDPE $(n=3)$ and U50,488H $(n=2)$ had very little or no effect in the cells tested (Fig. $8 B$ ). Because only a small percentage of GABA-type neurons responded to opioids with a direct effect and that too with a small current, we were unable to perform concentration-response curves with the agonists.

Thus, consistent with our hypothesis, GABA-type neurons that respond to $\mu$-opioid receptor agonists were found within the MSDB.

To corroborate the above electrophysiological findings, we performed immunostaining for the $\mu$-opioid receptor in MSDB neu- 

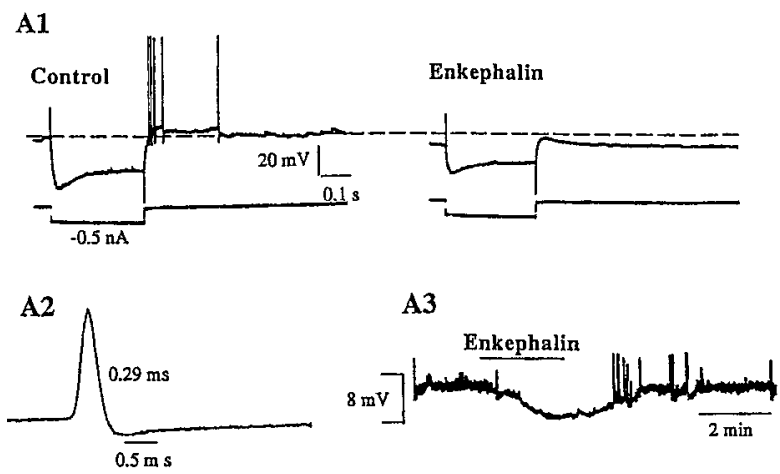

B
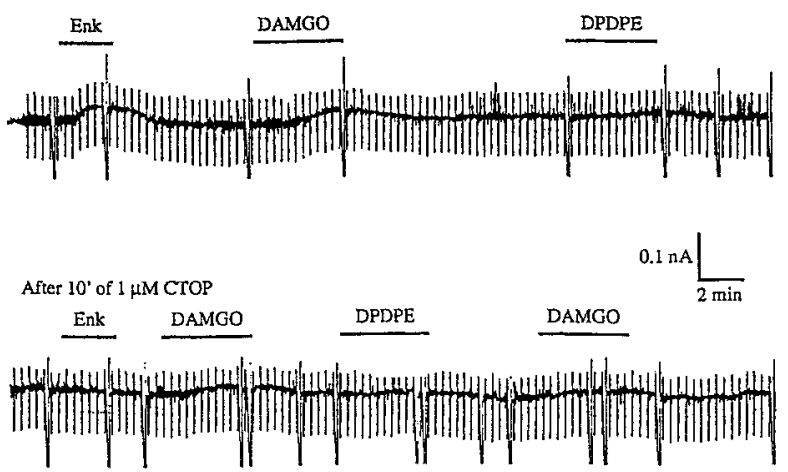

Figure 8. Opioids inhibit a subpopulation of GABA-type MSDB neurons and induce a direct, $\mu$ receptor-mediated outward current. $A 1, A 2$, Wholecell current-clamp recording from a GABA-type MSDB (spike duration, $0.29 \mathrm{msec}$ ). Also note the pronounced depolarizing sag in response to the hyperpolarizing pulses ( $0.5 \mathrm{nA}$ steps). $A 3$ shows the resting membrane potential recorded from the same cell. Note that the met-enkephalin effect reversed on washout. $B 1$ and $B 2$ show effect of different opioid receptor agonists in another GABA-type neuron that was voltage-clamped at -60 $\mathrm{mV}$ (characteristics not shown). Met-enkephalin produced a $50 \mathrm{pA}$ outward current. This effect was mimicked by the $\mu$-opioid receptor agonist DAMGO, but not by the $\delta$-receptor agonist DPDPE. The $\kappa$ receptor agonist U50488H also had no effect on this cell (data not shown). Pretreatment with the $\mu$ receptor antagonist CTOP blocked the inhibitory effects of met-enkephalin and DAMGO. Input conductance was measured by stepping the membrane potential to $-70 \mathrm{mV}$ for $1 \mathrm{sec}$ every $20 \mathrm{sec}$. Note that both met-enkephalin and DAMGO increased the input conductance of the cell. The taller intermittent deflections indicate the time at which the cell membrane was stepped to $-120 \mathrm{mV}$. In this cell, the opioid-induced outward current reversed near $E_{\mathrm{K}}(-92 \mathrm{mV}$; data not shown). Both the outward current and the accompanying conductance change were blocked by the opioid antagonist CTOP. An inhibitory effect of opioids was observed in $24.3 \%$ of GABA-type neurons tested; this effect persisted in the presence of TTX in the three cells tested.

rons and also combined it with immunolabeling for parvalbumin, a $\mathrm{Ca}^{2+}$-binding protein that is expressed only by septohippocampal GABA neurons in the MSDB (Freund, 1989) and hence has been used as a marker for septohippocampal GABA neurons.

\section{Immunostaining for $\mu$-opioid receptor in MSDB neurons}

Immunostaining for the $\mu$-opioid receptor resulted in a large number of immunopositive cells in the septum. In the lateral septum, the majority of these profiles could be observed in the dorsolateral area of this septal region. In contrast, in the MSDB complex, $\mu$-opioid receptor-containing cells were homogeneously distributed. Immunoreactivity was associated mostly with somata

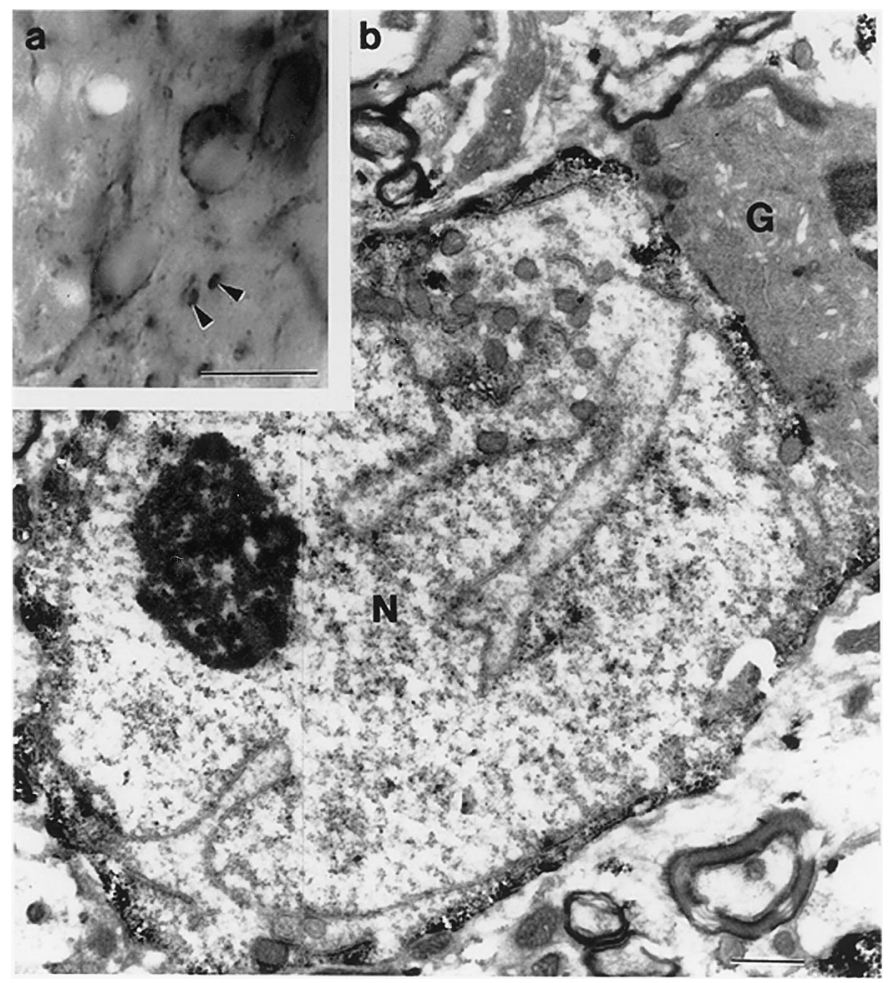

Figure 9. Light $(a)$ and electron $(b)$ micrographs demonstrate the result of immunostaining for $\mu$-opioid receptor in the medial septum. Immunoreactivity for $\mu$-opioid receptor is present in somata and large processes (arrowheads). The electron micrograph shows a $\mu$-opioid receptorimmunoreactive neuron $(N)$ characterized by an infolded nucleus. A neighboring glia cell $(G)$ is free of reaction product. Note that in the immunostained neuron, the reaction product is mostly associated with the inner cell membrane. Scale bars: $a, 20 \mu \mathrm{m} ; b, 1 \mu \mathrm{m}$.

and large processes (Fig. 9a), however, immunoreactive puncta could also be observed. Electron microscopic analysis performed exclusively on MSDB $\mu$-opioid receptor-immunoreactive cells revealed that all of these cells are neurons. The major characteristic of these neurons was that they contained infolded nuclei (Fig. $9 b)$. Glial elements were always immunonegative. In the somata of these immunopositive neurons, the immunoreaction was mostly associated with the inner surface of the cell membrane.

\section{Colocalization of $\mu$-opioid receptor and parvalbumin in MSDB neurons}

The colocalization studies were performed exclusively in the MSDB using two different types of experiments, double immunofluorescence and the "mirror" colocalization technique. First, a double immunofluorescence experiment was performed. The results of this colocalization seemed to indicate that a significant percentage of the $\mu$-opioid receptor-immunoreactive neurons of the medial septum co-contain parvalbumin, a calcium-binding protein (Fig. 10).

However, because the double immunofluorescence technique can lead to errors in interpretation because of the possibility of an overlap in the emission spectra of the fluorochromes, uncontrollable cross-reactivity between immunoreagents, and because of the quickness with which the fluorochromes fade under light microscopic examination (which makes an in-depth analysis very difficult), the mirror colocalization technique was also used. The mirror colocalization technique has the advantage of being absolutely specific because immunostaining for the two tissue antigens 

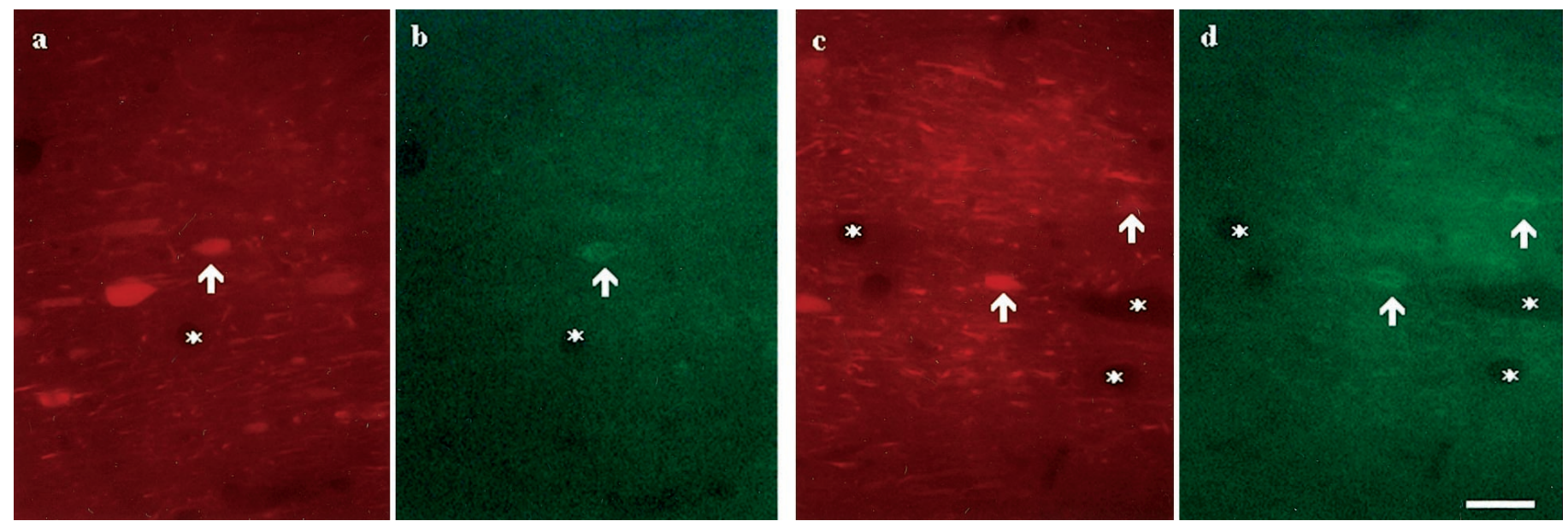

Figure 10. Colocalization of $\mu$-opioid receptor with parvalbumin-containing MSDB neurons using the technique of double immunofluorescence. Two pairs of color light micrographs ( $a$ and $b ; c$ and $d$ ) demonstrate three neurons (arrowheads) immunoreactive for both parvalbumin (immunolabeled with Texas Red; $a$ and $c$ ) and $\mu$-opioid receptor (immunostained with FITC; $b$ and $d$ ) in the medial septum. Asterisks label the same capillaries. Scale bar, $20 \mu \mathrm{m}$.
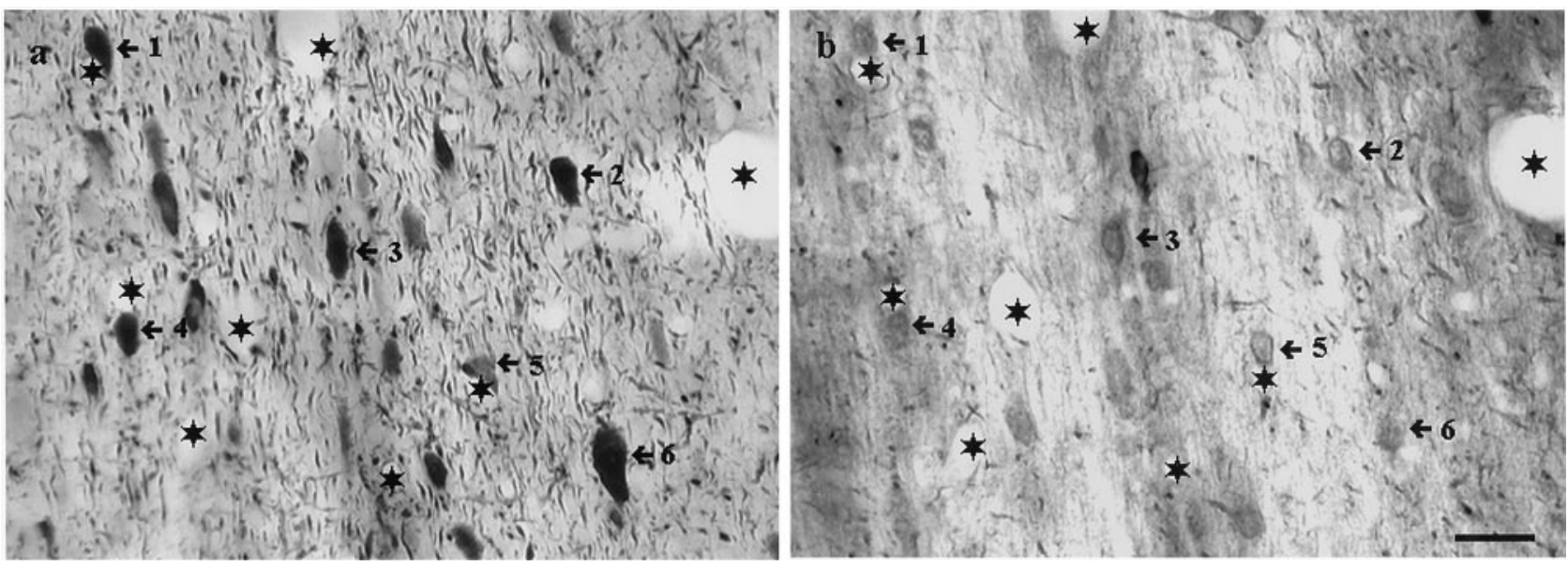

Figure 11. Colocalization of $\mu$-opioid receptor with parvalbumin-containing MSDB neurons using mirror colocalization technique. Light micrographs show the result of a mirror colocalization experiment for parvalbumin $(a)$ and $\mu$-opioid receptor $(b)$ on a pair of consecutive vibratome sections of the medial septal area. A large population (numbered arrows) of parvalbumin-immunoreactive neurons exhibits immunoreactivity for $\mu$-opioid receptor. Asterisks label identical capillaries. Scale bar, $20 \mu \mathrm{m}$.

is performed on separate sections. Sections from three animals (60 pairs of sections) were examined. This analysis revealed that $\sim 50 \%$ of the $\mu$-opioid receptor-immunopositive neurons demonstrated immunoreactivity for PA. Only $\sim 20 \%$ of the PAimmunopositive neurons of this area co-contained $\mu$-opioid receptors (Fig. 11).

Thus, consistent with electrophysiological findings a small subpopulation of septohippocampal GABAergic neurons were found to express the $\mu$-opioid receptor.

\section{DISCUSSION}

The main finding of this study is that opioids suppress inhibitory synaptic activity in both cholinergic and GABA-type medial septal/diagonal band neurons; this decrease in inhibitory activity results primarily from a direct $\mu$ receptor-mediated inhibition of a small subpopulation of GABA-type neurons that not only make numerous local connections but also project to the hippocampus. Thus, opioid effects in the MSDB are likely to have a profound effect on septal as well as septohippocampal functions.

\section{Opioids inhibit GABAergic neurons in the MSDB brain slice preparation}

In the present study, bath-applied met-enkephalin, a nonselective opioid agonist, decreased the frequency of spontaneously occurring inhibitory synaptic activity in both cholinergic and noncholinergic-type (presumably, GABAergic) MSDB neurons. The spontaneously occurring inhibitory synaptic potentials were blocked by bicuculline, a $\mathrm{GABA}_{\mathrm{A}}$ receptor antagonist. The change in the amplitude and polarity of the inhibitory synaptic currents was also consistent with changes in the $E_{\mathrm{Cl}^{-}}$. Thus, in recordings with gluconate-containing electrodes (calculated $E_{\mathrm{Cl}^{-}}=-80 \mathrm{mV}$ ), the amplitude of the spontaneously occurring synaptic currents decreased at more negative holding potentials and reversed polarity between -80 and $-100 \mathrm{mV}$, whereas with chloride-containing electrodes (calculated $E_{\mathrm{Cl}^{-}}=1.5 \mathrm{mV}$ ), the IPSCs were reversed in polarity and showed an increase in amplitude at more negative holding potentials. Additionally, opioid-sensitive IPSCs were blocked by tetrodotoxin (a fast sodium channel blocker), suggesting that in the MSDB opioids inhibit impulse-dependent GABA release.

The present study, however, does not rule out an additional 
effect of opioids on miniature IPSCs in MSDB neurons. As mentioned in the results, TTX-insensitive mIPSCs, representing terminal GABA release, were barely detectable under our lownoise (5-10 pA) experimental conditions in MSDB neurons. This is interesting as in the CA1 hippocampal pyramidal cells, opioidsensitive mIPSCs, which occur at frequencies of $2-20 \mathrm{~Hz}$ and are 5-100 pA in amplitude (which is above the noise level in our recordings), can be readily detected with $\mathrm{CsCl}$ or even with KCl-containing electrodes (Cohen et al., 1992; Lupica, 1995). The reason for this difference between the MSDB and the hippocampus remains unclear. Thus, the primary effect of opioids in MSDB neurons is to inhibit impulse-dependent GABA release that is caused by firing of GABAergic neurons.

It was also concluded that the opioid-induced changes in inhibitory synaptic activity result primarily from an inhibition of GABAergic neurons located within the MSDB because (1) opioids induced a similar decrease in IPSCs in slices in which the MSDB had been surgically isolated from all neighboring brain structures such as the lateral septum, confirming that opioid-inhibited IPSCs originate from within the MSDB; (2) spontaneously firing MSDB neurons that were inhibited by opioid agonists were found within the MSDB complex; and (3) in voltage-clamp recordings, GABA-type neurons that were directly inhibited by met-enkephalin in a tetrodotoxininsensitive manner were also found within the MSDB complex.

\section{The $\mu$-opioid receptor mediates the effect of met- enkephalin on MSDB GABAergic neurons}

It was concluded that the $\mu$-opioid receptor mediates the effect of met-enkephalin on MSDB GABAergic neurons because the $\mu$ but not the $\delta$ or $\kappa$ receptor agonists mimicked the observed effects of met-enkephalin and decreased the frequency of bicuculline and TTX-sensitive spontaneously occurring IPSCs both in preparations containing the MSDB and neighboring brain structures as well as in preparations containing only the MSDB. Similarly, the $\mu$ agonist also mimicked the effect of met-enkephalin and blocked the activity of spontaneously firing MSDB neurons recorded extracellularly, it also mimicked the direct effect of metenkephalin in GABA-type neurons and produced a TTXinsensitive outward current. These findings are consistent both with the high levels of $\mu$ receptor binding (Goodman and Pasternak, 1985; Mansour et al., 1988) and receptor mRNA (Delfs et al., 1994; Mansour et al., 1994; Zastawny et al., 1994) in the MSDB. A similar opioid receptor-mediated decrease in sIPSCs as a result of inhibition of GABAergic neurons has been reported in other areas of the brain such as the hippocampus (Zieglgansberger et al., 1979; Nicoll et al., 1980; Siggins and Zieglgansberger, 1981; Cohen et al., 1992), the ventral tegmental area (Johnson and North, 1992), and the nucleus accumbens (Yuan et al., 1992).

Within the MSDB the GABAergic neurons inhibited by $\mu$-opioids could belong to the subpopulation of GABAergic neurons that contains the $\mathrm{Ca}^{2+}$-binding protein parvalbumin and projects to the hippocampus (Freund, 1989) and/or to the second subpopulation that does not project outside of the nucleus. Because we observed a $\mu$-opioid-induced decrease in local synaptic activity in slices that contained only the MSDB, we concluded that the $\mu$-opioid-inhibited MSDB GABAergic neurons make numerous local circuit connections. Anatomically, the presence of such local connections has been much speculated about because parvalbumin-immunoreactive terminals have been found around both parvalbumin-positive and parvalbumin-negative MSDB structures (Leranth et al., 1992; Gao et al., 1995). The results of the present study and our previous studies on the effects of serotonin and norepinephrine on MSDB neurons
(Alreja, 1996; Alreja and Liu, 1996) provide strong evidence for the presence of such local connections.

\section{$\boldsymbol{\mu}$-Opioids inhibit septohippocampal GABA neurons}

Interestingly, in addition to making local synaptic connections, the results of the present study indicate that opioid-activated MSDB neurons also project to the hippocampus. This conclusion is based on the results of our antidromic activation studies on septohippocampal neurons, which indicate that opioids inhibit septohippocampal neurons. Additionally, the evidence presented in this study indicates that the opioid agonist-inhibited septohippocampal neurons are most likely GABAergic in nature. This is suggested by the short antidromic activation latencies of the opioid-responsive neurons and thus higher mean conduction velocities (mean, $1.83 \pm 0.14 \mathrm{~m} / \mathrm{sec}$; range, $1.1-3.2 \mathrm{~m} / \mathrm{sec}$ ). Conduction velocities in this range have previously been reported to represent the thickly myelinated, faster-conducting GABAergic fibers (Freund, 1989; Miller and Freedman, 1993). In contrast, the unmyelinated or lightly myelinated cholinergic SHNs have much slower conducting fibers $(<0.3 \mathrm{~m} / \mathrm{sec})$. The conclusion, that the opioid-inhibited SHNs are indeed GABAergic in nature is also supported by our anatomical colocalization studies using doubleimmunofluorescence as well as the mirror colocalization technique (which has absolute specificity) where we found that a small subpopulation $(\sim 20 \%)$ of parvalbumin-containing neurons expresses the $\mu$-opioid receptor. As mentioned before, parvalbumin is a $\mathrm{Ca}^{2+}$-binding protein, that in the MSDB, is expressed exclusively by septohippocampal GABAergic neurons (Freund, 1989). At the ultrastructural level we found that the $\mu$-opioid receptor in MSDB neurons is localized to the somatic as well as dendritic membranes. The finding that only a small subpopulation of parvalbumin-containing MSDB neurons expressed the $\mu$-opioid receptor $(\sim 20 \%)$ corroborates our electrophysiological findings where only a small subpopulation of GABA-type MSDB neurons were found to be directly inhibited by opioids.

\section{Significance of the findings}

An opioid-induced inhibition of septohippocampal GABAergic SHNs is likely to have a significant effect on hippocampal function as the GABAergic projection neurons of the MSDB innervate almost every type of hippocampal interneuron (Freund and Antal, 1988). Through this connectivity, electrical stimulation of septohippocampal GABAergic afferents has been shown to selectively inhibit hippocampal inhibitory cells and so disinhibit pyramidal cells (Toth et al., 1997). An opioid-induced inhibition of septohippocampal GABAergic neurons, as was observed in this study, would therefore disinhibit a large number of hippocampal GABAergic neurons and increase both feedback and feedforward type of local hippocampal inhibition (Freund and Antal, 1988). The resultant decrease in pyramidal cell excitability could decrease the likelihood for the induction of long-term potentiation (LTP) because LTP can be preferentially induced when the cells are maximally stimulated (Pavlides et al., 1988). Such effects could therefore explain the memory impairment that is observed after intraseptal injections of opioids (see introductory remarks). The results of the present study also show that opioids by decreasing the release of GABA would result in a disinhibition of a subpopulation of cholinergic neurons. Whether this disinhibition is opposed by any direct inhibitory effects of opioids on cholinergic neurons is currently being investigated in our laboratory.

In addition to its impact on septohippocampal circuitry and associated learning and memory-related processes, the $\mu$ receptor-mediated inhibitory effects of opioids in the MSDB may 
also contribute to the addictive properties of opioids (see introductory remarks).

In conclusion, the results of the present study suggest that $\mu$ opioids via their actions on MSDB GABAergic neurons are likely to not only have profound local effects on septal circuitry (by virtue of a large number of local circuit connections) but would also strongly influence hippocampal function via the septohippocampal pathway.

\section{REFERENCES}

Alreja M (1996) Excitatory actions of serotonin on GABAergic neurons of the medial septum and diagonal band of Broca. Synapse 22:15-27.

Alreja M, Aghajanian GK (1995) Intracellular diffusion of macromolecules through patch pipettes in brain slices. In: Brain slices in basic and clinical research (Schurr A, Rigor BM, eds), pp 117-130. Boca Raton, FL: CRC.

Alreja M, Liu W (1996) Noradrenaline induces IPSCs in rat medial septal/diagonal band neurons: involvement of septohippocampal GABAergic neurons. J Physiol (Lond) 494:201-215.

Baldino Jr F, Beckman AL (1982) An analysis of the origins of the cholinergic and non-cholinergic septal projections to the hippocampal formation of the rat. Brain Res 232:247-252.

Bloom FE, Rossier J, Battenberg ELF, Bayon A, French E, Henriksen SJ, Siggins GR, Segal D, Browne R, Ling N, Guillemin R (1978) $\beta$-endorphin: cellular localization, electrophysiological and behavioral effects. In: Advances in biochemical psychopharmacology (Costa E, Trabucchi M, eds), pp 89-109. New York: Raven.

Bostock E, Gallagher M, King RA (1988) Effects of opioid microinjections into the medial septal area on spatial memory in rats. Behav Neurosci 106:643-652.

Bot G, Chahl L (1996) Induction of Fos-like immunoreactivity by opioids in guinea-pig brain. Brain Res 731:45-56.

Botticelli LR, Wurtman RJ (1982) Septohippocampal cholinergic neurons are regulated transsynaptically by endorphin and corticotropin neuropeptides. J Neurosci 2:1316-1321.

Bozarth MA (1983) Opiate reward mechanisms mapped by intracranial self-administration. In: The neurobiology of opiate reward processes (Smith JE, Lane JD, eds), pp 331-359. Amsterdam: Elsevier Biomedical.

Carette B, Poulain P (1982) Postsynaptic inhibitory effects of Met- and Leu-enkephalin on endocrine and adjacent neurones in the preopticseptal region of the guinea pig. Peptides 3:125-133.

Cohen GA, Doze VA, Madison DV (1992) Opioid inhibition of GABA release from presynaptic terminals of rat hippocampal interneurons. Neuron 9:325-335.

Costa E, Panula P, Thompson HK, Cheney DL (1983) The transsynaptic regulation of the septal-hippocampal cholinergic neurons. Life Sci 32:165-179.

Couceyro P, Douglass J (1995) Precipitated morphine withdrawal stimulates multiple activator protein-1 signaling pathways in rat brain. Mol Pharmacol 47:29-39.

Delfs JM, Kong H, Mestek A, Chen Y, Yu L, Reisine T, Chesselet MF (1994) Expression of mu opioid receptor mRNA in rat brain: an in situ hybridization study at the single cell level. J Comp Neurol 345:46-68.

Finley JCW, Lindstrom P, Petrusz P (1981) Immunocytochemical localization of $\beta$-endorphin-containing neurons in the rat brain. Neuroendocrinology 33:28-42.

French ED, Siggins GR (1980) An iontophoretic survey of opioid peptide actions in the rat limbic system: in search of opiate epileptogenic mechanisms. Regul Pept 1:127-146.

Freund T (1989) GABAergic septohippocampal neurons contain parvalbumin. Brain Res 478:375-381.

Freund TF, Antal M (1988) GABA-containing neurons in the septum control inhibitory interneurons in the hippocampus. Nature 336:170-173.

Gao B, Hornung JP, Fritschy JM (1995) Identification of distinct $\mathrm{GABA}_{\mathrm{A}}$-receptor subtypes in cholinergic and parvalbumin-positive neurons of the rat and marmoset medial-septum diagonal band complex. Neuroscience 65:101-117.

Goodman RR, Pasternak GW (1985) Visualization of $\mu_{1}$ opiate receptors in rat brain by using a computerized autoradiographic subtraction technique. Proc Natl Acad Sci USA 82:6667-6671.

Gorelova N, Reiner PB (1996) Role of the afterhyperpolarization in control of discharge properties of septal cholinergic neurons in vitro. J Neurophysiol 75:695-706.
Griffith WH (1988) Membrane properties of cell types within guinea pig basal forebrain nuclei in vitro. J Neurophysiol 59:1590-612.

Griffith WH, Matthews RT (1986) Electrophysiology of AChE-positive neurons in basal forebrain slices. Neurosci Lett 71:169-174.

Johnson SW, North RA (1992) Opioids excite dopamine neurons by hyperpolarization of local interneurons. J Neurosci 12:483-488.

Kimes AS, London ED (1988) Glucose utilization in the rat brain during chronic morphine treatment and naloxone-precipitated morphine withdrawal. J Pharmacol Exp Ther 248:538-545.

Kosaka T, Kosaka K, Tateishi K, Hamaoka Y, Yamaihara M, Wu JY, Hama K (1985) GABAergic neurons containing CCK-8-like and/or VIP-like immunoreactivities in the rat hippocampus and dentate gyrus. J Comp Neurol 239:420-430.

Lamour Y, Dutar P, Jobert A (1984) Septo-hippocampal and other medial septum diagonal band neurons: electrophysiological and pharmacological properties. Brain Res 309:227-239.

Leranth C, Deller T, Buzsaki G (1992) Intraseptal connections redefined: lack of a lateral septum to medial septum path. Brain Res 583:1-11.

Liu W, Alreja M (1997) Atypical antipsychotics block the excitatory effects of serotonin in septohippocampal neurons in the rat. Neuroscience 79:369-382.

Liu W, Kumar A, Alreja M (1998) Excitatory effects of muscarine on septohippocampal neurons: Involvement of $\mathrm{M}_{3}$ receptors. Brain Res 805:220-233.

Lupica CR (1995) $\delta$ and $\mu$ enkephalins inhibit spontaneous GABAmediated IPSCs via a cyclic AMP-independent mechanism in the rat hippocampus. J Neurosci 15:737-749.

Mansour A, Khachaturian H, Lewis ME, Akil H, Watson SJ (1988) Anatomy of CNS opioid receptors. Trends Neurosci 11:308-314.

Mansour A, Fox CA, Thompson RC, Akil H, Watson SJ (1994) $\mu$-Opioid receptor mRNA expression in the rat CNS: comparison to $\mu$-receptor binding. Brain Res 643:245-265.

Markram H, Segal M (1990) Electrophysiological characteristics of cholinergic and non-cholinergic neurons in the rat medial septum-diagonal band complex. Brain Res 513:171-174.

Millan MH, Millan MJ, Przewlocki R (1984) Lesions of the hypothalamic arcuate nucleus modify discrete brain and pituitary pools of dynorphin in addition to $\beta$-endorphin in the rat. Neurosci Lett 48:149-154.

Miller CL, Freedman R (1993) Medial septal neuron activity in relation to an auditory sensory gating paradigm. Neuroscience 55:373-380.

Moroni F, Cheney DL, Costa E (1978) The turnover rate of acetylcholine in brain nuclei of rats injected intraventricularly and intraseptally with alpha and beta-endorphin. Neuropharmacology 17:191-196.

Nicoll RA, Alger BE, Jahr CE (1980) Enkephalin blocks inhibitory pathways in the mammalian CNS. Nature 287:22-25.

Pavlides C, Greenstein YJ, Grudman M, Winson J (1988) Long-term potentiation in the dentate gyrus is induced preferentially on the positive phase of theta-rhythm. Brain Res 439:383-387.

Ragozzino ME, Parker ME, Gold PE (1992) Spontaneous alternation and inhibitory avoidance impairments with morphine injections into the medial septum. Attenuation by glucose administration. Brain Res 597:241-249.

Siggins GR, Zieglgansberger W (1981) Morphine and opioid peptides reduce inhibitory synaptic potentials in hippocampal pyramidal cells in vitro without alteration of membrane potential. Proc Natl Acad Sci USA 78:5235-5239.

Stein EA, Olds J (1977) Direct intracerebral self-administration of opiates in the rat. Soc Neurosci Abstr 3:302.

Toth K, Freund TF, Miles R (1997) Disinhibition of rat hippocampal pyramidal cells by GABAergic afferents from the septum. J Physiol (Lond) 500:463-74.

Van Der Kloot W (1991) The regulation of quantal size. Prog Neurobiol 36:93-130.

Watson SJ, Barchas JD, Li CH (1977) $\beta$-Lipotropin: localization of cells and axons in rat brain by immunocytochemistry. Proc Natl Acad Sci USA 74:5155-5158.

Yuan X, Madamba S, Siggins GR (1992) Opioid peptides reduce synaptic transmission in the nucleus accumbens. Neurosci Lett 134:223-228.

Zastawny RL, George SR, Nguyen T, Cheng R, Tsatsos J, BrionesUrbina R, O'Dowd BF (1994) Cloning, characterization, and distribution of a $\mu$-opioid receptor in rat brain. J Neurochem 62:2099-2105.

Zieglgansberger W French ED Siggins GR and Bloom FE (1979) Opioid peptides may excite hippocampal pyramidal neurons by inhibiting adjacent inhibitory interneurons. Science 205:415-417. 